\title{
Thermo-responsive PNIPAm-based Composite Nanofibers Prepared by Electrospinning
}

\author{
Libo Deng ${ }^{*}$, Jiaxiang Chen, Zhipeng Zhang, and Weijia Zeng \\ College of Chemistry and Environmental Engineering, Shenzhen University, Shenzhen 518060, China \\ *E-mail: Denglb@ szu.edu.cn
}

doi: $10.20964 / 2018.08 .63$

Received: 29 April 2018 / Accepted: 12 June 2018 / Published: 5 July 2018

Flexible and wearable electronics capable of detecting the temperature, the motion and the stress in the body have been developing recently. Such devices rely heavily on the stimuli-responsive materials. Particularly, flexible materials which can give electrical response to the change of temperature are crucial for wearable healthcare electronics, and thus have received great research interests recently. Herein, a thermo-responsive copolymer was prepared by copolymerization between $\mathrm{N}$ isopropylacrylamide (NIPAm) and $\mathrm{N}$-methylol acrylamide (NMA). $\mathrm{AgNO}_{3}$ was mixed with the P(NIPAm-co-NMA) solution to fabricate nanofibers by electrospinning, which was then converted into $\mathrm{Ag}$ by in-situ reduction with sodium borohydride. The electrical resistance of the composite nanofiber showed high sensitivity to the change of temperature. Furthermore, the composite nanofibers exhibited excellent stability during repeated heating-cooling cycles.

Keywords: Thermo-responsive material; nanofiber; in-situ reduction; copolymerizatio

\section{FULL TEXT}

(C) 2018 The Authors. Published by ESG (www.electrochemsci.org). This article is an open access article distributed under the terms and conditions of the Creative Commons Attribution license (http://creativecommons.org/licenses/by/4.0/). 